\title{
IATROGENIA INSTITUCIONAL Y MUERTE MATERNA. SEMMELWEIS Y LA FIEBRE PUERPERAL
}

\author{
Oswaldo Salaverry García ${ }^{1,2, a}$
}

\section{RESUMEN}

La fiebre puerperal es una enfermedad que asume carácter epidémico en el siglo XVIII como consecuencia de dos factores: las masas trabajadoras urbanas generadas por la revolución industrial, y la progresiva hegemonización y medicalización de la atención del parto en grandes hospitales públicos. La mortalidad materna institucionalizada alcanza cifras superiores al $30 \%$, en tanto con la atención por parteras es menor al $2 \%$. Semmelweis, médico húngaro, postula que los médicos contaminaban a las parturientas por insuficiente higiene luego de realizar necropsias, e implanta medidas profilácticas en el Hospital de Viena, las cuales reducen dramáticamente la mortalidad, pero sus ideas son rechazadas por que afectan el proceso de institucionalización de la medicina basado en el altruismo y honor, por los que supuestamente era imposible que causen daño a sus pacientes. Es obligado a retirarse del Hospital de Viena, y continua su lucha en Budapest, pero el rechazo y la incomprensión de sus colegas por su doctrina afecta su salud mental. Muere en un asilo, pocos años antes que Pasteur y Koch demuestren las bacterias causantes de enfermedades como la fiebre puerperal.

Palabras clave: Infección puerperal; Mortalidad materna; Mortalidad hospitalaria; Historia de la medicina (Fuente DeCS BIREME)

\section{INSTITUTIONAL IATROGENY AND MATERNAL DEATH. SEMMELWEIS AND PUERPERAL FEVER}

\begin{abstract}
Puerperal fever is a disease that becomes epidemic in the eighteenth century as a result of two factors: the urban working masses generated by the industrial revolution and the progressive hegemonization and medicalization of birth care in large public hospitals. Institutionalized maternal death reached figures above $30 \%$, while in the case of birth care provided by midwives, it was than $2 \%$. Semmelweis, an Hungarian physician, sustained that physicians contaminated women in labor due to insufficient hygiene after performing necropsies and established prophylactic measures in the Vienna Hospital that reduced mortality dramatically. However, his ideas were rejected because they affected the institutionalization process of medicine, based on altruism and honor, which would make it impossible to cause harm to patients. He was forced to leave Vienna Hospital and he continued his struggle in Budapest, but the rejection and disagreement of his peers with his doctrine affected his mental health. He died in an asylum, a few years before Pasteur and Koch proved the existence of the bacteria that caused diseases such as puerperal fever.
\end{abstract}

Key words: Puerperal infection; Maternal mortality; Hospital mortality; History of medicine (source: MeSH NLM).

\section{INTRODUCCIÓN}

En 1847, una de cada seis mujeres que daban a luz en el Hospital General de Viena (Allgemeines Krankenhaus der Stadt Wien) moría de una extraña enfermedad denominada entonces fiebre puerperal que se desarrollaba sin prolegómeno alguno poco después del parto y que luego de una larga y dolorosa agonía dejaba una secuela de jóvenes madres muertas y nuevos huérfanos. Otras parturientas eran más afortunadas, y si bien desarrollaban los primeros síntomas de la enfermedad con dolor abdominal, fiebre, y descargas vaginales fétidas, luego sin intervención alguna de los médicos o medicamento que fuera de comprobada utilidad, lograban recuperarse, casi milagrosamente.

Lo que ocurría en el Hospital de Viena se repetía en todos los hospitales europeos y la disputa que surgió alrededor de la causa de la enfermedad y el rol que desempeñaban los médicos en su difusión, nos permite analizar el complejo proceso de institucionalización de la medicina como disciplina hegemónica de la salud en el contexto de

Centro Nacional de Salud Intercultural, Instituto Nacional de Salud. Lima, Perú.

Facultad de Medicina, Universidad Nacional Mayor de San Marcos. Lima, Perú.

Médico, doctor en medicina

Recibido: 12-08-13 Aprobado: 21-08-13

Citar como: Salaverry García O. Iatrogenia institucional y muerte materna. Semmelweis y la fiebre puerperal. Rev Peru Med Exp Salud Publica. 2013;30(3):512-7. 
una sociedad y época marcada por el concepto de honor y una visión cuasi religiosa del acto médico.

\section{FIEBRE PUERPERAL Y MEDICALIZACIÓN DEL PARTO}

La fiebre puerperal ya había sido descrita claramente en la antigüedad por Hipócrates, aunque sin darle un nombre específico. La atribuía a un flujo anormal de los loquios /... Cuando a una mujer que acaba de dar a luz le vienen los loquios, le viene con dificultad, pues la matriz está inflamada y su orificio cerrado. $Y$ es que después de que la criatura ha efectuado su salida, la abertura del genital se curva. Cuando ocurra esto, la purgación no bajará y si no le baja, acabará por tener fiebre, escalofríos y el vientre hinchado. Cuando alguien la toque sentirá dolor en todo el cuerpo, sobre todo si se le toca el vientre... si el vientre no se le remueve y la purgación no le baja espontáneamente, si tampoco se le aplican enseguida los remedios que convienen y el tiempo transcurre, todo lo que acabo de decir acentuará más su virulencia y, además, corre el peligro de ponerse lívida como el plomo e hidrópica, el ombligo le saldrá hacia afuera empujado por la matriz y será más oscuro que las partes circundantes. Cuando se presentan todos estos síntomas las enfermas no logran sobrevivir y unas mueren más pronto, otras más tarde según sea el estado de su cuerpo y de su enfermedad (1).

La descripción hipocrática es clínicamente exacta y su explicación, de carácter mecánico (una obstrucción de los loquios) se mantuvo vigente durante más de mil años. En el Medioevo, autores clásicos, como el médico islámico Avicena, la aceptaron y, aunque tampoco le dieron un nombre específico, relataron casos observados, siempre esporádicos. La medicina renacentista pese a su progresivo alejamiento de la ortodoxia clásica no añadió nada nuevo, mantuvo la explicación tradicional. En el siglo XVII se inicia el interés de los médicos en las enfermedades de las mujeres y el parto buscando sistematizar las distintas dolencias posparto, entre las cuales se incluyó la fiebre puerperal, aun considerada una enfermedad esporádica. Surgen nuevas explicaciones como la de Plateri, en 1662, quien la atribuye a la introducción de aire frío en el útero a consecuencia de un parto en un ambiente insuficientemente caldeado, lo cual inflamaría el útero y provocaría los síntomas ${ }^{(2)}$. Otra teoría involucraba a la sangre menstrual, la que durante el embarazo "nutría" al feto y luego en el posparto se convertía en leche que era conducida a las mamas por un conducto nunca descubierto anatómicamente. Obstruido el flujo, la leche materna se retenía, entraba en putrefacción y se diseminaba retrógradamente a diversas partes del organismo, en particular hacia el útero y el abdomen causando la fiebre puerperal. Las necropsias de las victimas aparentemente apoyaban esta interpretación pues mostraban grandes colecciones purulentas en útero y abdomen que semejaban leche materna.

Durante el siglo XVII el parto era atendido por las comadronas, parteras o recibidoras, todas ellas sin una formación científica o escolarizada, excepcionalmente intervenía un cirujano en caso de muerte fetal o materna para salvar bien sea a la madre o al feto. En el siglo XVIII el proceso de institucionalización hegemónica de la medicina universitaria, que se desarrolla desde la cátedra de medicina, incorpora paulatinamente las enfermedades de las mujeres y también el parto, la medicina se aleja del galenismo y dirige hacia la medicina moderna ${ }^{(3)}$. En ese proceso se descalifica a las parteras indicando su poca destreza o ignorancia. Los cirujanos, entonces una profesión distinta a la medicina, se suman a estos ataques; por una parte ya existían parteros o accoucheurs que se acercaban hacia la cirugía y por otra parte algunos cirujanos encuentran un nuevo y lucrativo mercado en las enfermedades del parto; estos, sin embargo, tienen un público diferente, atienden solo a los burgueses o miembros de la nobleza, mientras

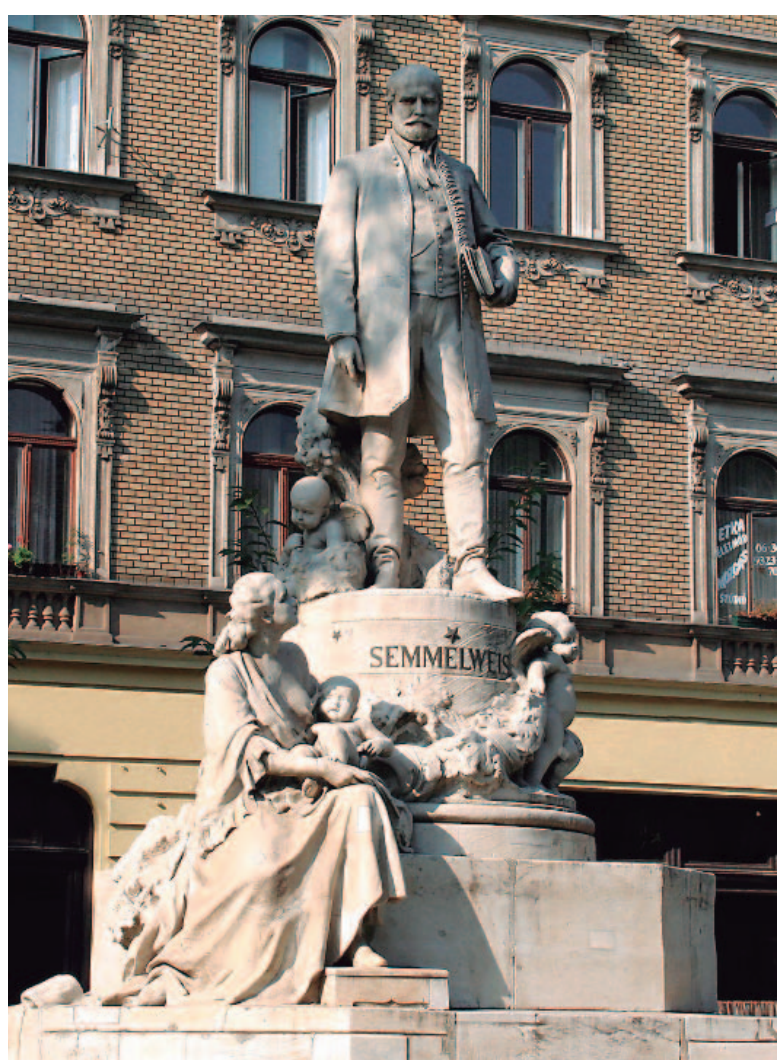

Figura 1. Monumento al médico Ignaz Semmelweis en Budapest, el cual representa a las madres y a los niños que se salvaron gracias a su lucha. 
el pueblo continúa atendiéndose con las comadronas. Un ejemplo es el de Jules Clément (1649-1729) quien atendió el parto de la delfina o hija de Luis XIV (4).

Las enfermedades febriles posparto son incluidas en el estudio de las "fiebres" en general; al clasificarlas, un médico inglés, Strother, acuña en 1716 el nombre de "fiebre puerperal", manteniendo como causa la supresión de los loquios ${ }^{(5)}$. Los reportes de esta enfermedad se incrementan desde mediados del siglo XVIII, paralelamente al incremento de su incidencia ${ }^{(6)}$. Se identifica una constante: las epidemias siempre ocurren en hospitales, nunca cuando el parto se atiende en casa por comadronas. La primera epidemia claramente identificada ocurrió en el Hôtel Dieu en febrero de 1746 donde murieron en un solo mes veinte parturientas, repitiéndose cifras similares durante los siguientes meses ${ }^{(7)}$.

La revolución industrial de la segunda mitad del XVIII acelera el proceso de urbanización y las masas trabajadoras dependen de hospitales públicos para su atención de salud. Estos se ven atiborrados de enfermos, pero además deben prestar el nuevo servicio de maternidad. Se crean hospitales-maternidad (Lying Hospitals) o secciones de maternidad en hospitales generales atendidos por médicos, lo cual es el origen de la paulatina introducción de la postura horizontal del parto reemplazando la postura vertical o semivertical. Hasta entonces los partos, domiciliarios casi todos, se realizaban en sillas inclinadas y por una partera. La medicalización del parto en zonas urbanas asimila este proceso natural a las cirugías convencionales realizándolo en posición horizontal. No es este el único cambio; la introducción de la mentalidad anatomopatológica, iniciada por Morgagni, entroniza la necropsia como base previa de la clínica debiendo explicar los signos y síntomas. Los hospitales, como centros de formación profesional, difunden este modelo; se inician las necropsias sistemáticas a todos los fallecidos, incluyendo las muertes maternas por fiebre puerperal buscando descubrir su origen.
Las condiciones hospitalarias de la época eran terribles, era frecuente que tres y hasta cinco pacientes compartieran una misma cama; la suciedad, el hacinamiento y la escasez de personal era lo común pero aun en esas condiciones, con una alta mortalidad general, destacaba la fiebre puerperal como causa de muerte. Más que la prevención, la naturaleza de la enfermedad era, sin embargo, lo que preocupaba a los médicos ya que las necropsias muestran siempre el mismo cuadro. Se discuten dos interpretaciones generales: las que consideran su origen como pútrido y otros un origen inflamatorio. Los primeros continúan postulando los loquios o la sangre retenida, o en una forma más elaborada la éstasis intestinal propia del embarazo, que induciría la formación de sustancias pútridas que llegarían a la sangre. La interpretación inflamatoria considera una influencia externa que actúa sobre los órganos genitales, que produciría pus que alcanza diversas cavidades. En algo coincidían ambas explicaciones: la causa de la fiebre puerperal era responsabilidad de la mujer, no del médico pese a la evidencia de que la epidemia solo ocurría en los partos hospitalarios atendidos por médicos.

Hulme, hacia 1772 en $A$ treatise on puerperal fever ${ }^{(8)}$ revisa el tema y concluye que la fiebre puerperal se ha convertido en una epidemia femenina específica, diferente a otras fiebres posparto, proponiendo un cuadro diagnóstico diferencial (Tabla 1). Partidario de la teoría del éstasis intestinal, señala como una de sus causas el uso de corsés apretados en los primeros meses del embarazo ${ }^{(9)}$, insistiendo así en la responsabilidad de la mujer.

Gordon, en 1795 reporta la epidemia ocurrida en Aberdeen entre 1789 y 1792 y postula el carácter contagioso de la enfermedad, la que sería transmitida de una paciente a otra por quien atiende el parto ${ }^{(10)}$. Su obra $A$ treatise on the epidemic puerperal fever of Aberdeen es un ejercicio de honestidad intelectual; reconoce el gran desconocimiento de los médicos sobre la enfermedad y que ellos mismos

Tabla 1. Diagnóstico diferencial de la fiebre puerperal en el siglo XVIII según Hulme

\begin{tabular}{|c|c|c|}
\hline Dolencia & Traducción & Diagnóstico diferencial \\
\hline After pains & Posparto & No hay fiebre, ni sensibilidad exquisita del abdomen, el dolor no es periódico \\
\hline Milk fever & Fiebre de la leche & No presenta dolor y sensibilidad abdominal. Presenta turgencia mamaria \\
\hline Miliary fever & Fiebre miliar & $\begin{array}{l}\text { El dolor es generalizado, no hipogástrico, presenta una menor alteración del } \\
\text { sensorio y no suele presentar erupciones }\end{array}$ \\
\hline Illiac passions & Dolencia iliaca & Por el dolor localizado, no adopta posiciones antalgicas. \\
\hline Flatulent colic & Cólico flatulento & El dolor no migra \\
\hline Inflamation of the uterus & Inflamación uterina & Falta la sensación de peso o masa y de ardor desde el útero hacia la periferia \\
\hline Cholera morbus & Cólera & Por la marcada diarrea del cólera \\
\hline
\end{tabular}

Fuente: Hulme ${ }^{(8)}$ 
podían ser los causantes de aquella: /... Es una declaración desagradable para mí mencionar, que yo mismo era el medio para llevar la infección a un gran número de mujeres ${ }^{(11)}$. Creía que el "contagio" era provocado por una cierta "atmosfera" que rodeaba a quienes atendían a una enferma y que luego transmitían a la siguiente parturienta: /... Cada persona, que había estado con un paciente con fiebre puerperal, se cargó de una atmosfera de infección, que transmitió a todas las mujeres embarazadas. Es el primero en proponer medidas preventivas: fumigar ambientes, incinerar ropas de cama y el cambio o muda de ropa de los médicos entre una atención y la siguiente. Mantuvo, sin embargo una terapéutica tradicional con sangrías abundantes en el entendido que así eliminaba el agente pútrido que había alcanzado la sangre. Su propuesta no tuvo difusión y fue olvidada por los médicos, pero no por la población que a confesión de parte de su responsabilidad en estas muertes abandonó su consulta debiendo Gordon reengancharse en la Marina donde anteriormente había servido para finalmente morir de tuberculosis a los 46 años.

\section{CONTAGIO E INFECCIÓN: IGNAZ SEMMELWEIS}

Las muertes maternas por fiebre puerperal alcanzaron cifras dramáticas en la primera mitad del XIX; entre 1831 y 1843 la mortalidad materna en Londres era de 10 por 10000 partos cuando el parto era domiciliario y de 600 por 10000 en el Lying Hospital, similares estadísticas se repetían por toda Europa ${ }^{(12)}$. Pese a esa evidencia, las explicaciones nunca apuntaban al médico, se postulaba la existencia de un ambiente pútrido en los hospitales, contagio desde otros pacientes concurrentes ${ }^{(13)}$, causas estacionales, uso de prendas apretadas por las embarazadas ${ }^{(14)} y$ hasta al sonido de las campanas ${ }^{(15)}$. En ese contexto Viena, y su Hospital General, el Allgemeine Krankenhouse eran, a comienzos del XIX, una excepción; el índice de mortalidad materna era de menos del 1\%; debido a que su jefe el Dr. Johann Boër era partidario de una mínima intervención médica en los partos, proscribía el forceps y además limitaba las necropsias. Desde 1824 es reemplazado por el Dr. Johann Klein (1788-1856) quien siguiendo lo usual en toda Europa, reinstauró las necropsias e inmediatamente subió la mortalidad hasta 7,5 \%. En 1834 inauguró una segunda división materna que desde 1839 fue atendida solo por parteras y las estadísticas comenzaron a diferenciarse: crecientes muertes maternas en la primera división atendida por médicos y bajos índices en la segunda división manejada por las parteras.

Estas cifras se daban a pesar que a mediados del siglo XIX el Allgemeine Krankenhouse de la Universidad de
Viena era el centro más prestigioso para la enseñanza e investigación médica. Karl Rokitanski el gran patólogo y Josef Skoda, el clínico, eran figuras centrales alrededor de los cuales gravitaba una constelación de destacados discípulos provenientes de toda Europa, uno de ellos fue el protagonista del cambio: Ignaz Semmelweis.

Semmelweis nace en Pest, Hungría, en 1818. Su lengua materna era un dialecto germánico Suabo, que luego completaría con el húngaro dándole un peculiar acento que sonaba extraño tanto a alemanes como a húngaros. Luego de unos estudios accidentados entre Pest y Viena se graduó de medico por la Universidad de Viena en 1844. Bajo la protección de Rokitansky permanece en la universidad y realiza necropsias de víctimas de la fiebre puerperal, obtiene un diploma de maestro de partos y gana un concurso como asistente del profesor Klein, jefe de la primera división de la maternidad. Inicia sus labores en julio de 1846, con la firme decisión de encontrar una medida que evitara más muertes maternas, pero entra en conflicto con Klein, quien creía inútil cualquier cambio y consideraba la alta tasa de muertes como algo inevitable. Luego de cuatro meses debió retirarse porque su predecesor como asistente, el Dr. Breit, obtuvo una prórroga de su servicio. Dos años después Breit fue nombrado profesor de obstetricia en Tubinga, y Semmelweis reasume funciones el 20 de marzo de 1847. Lo recibió una mala noticia: durante una necropsia a una víctima de fiebre puerperal un estudiante había herido accidentalmente en la mano al profesor Joseph Koletchska, quien luego de algunos días murió con los signos de fiebre puerperal, lo que se confirmó con la necropsia.

Semmelweis encontró la explicación que buscaba y daba sentido a sus investigaciones, básicamente estadísticas, que demostraban que los médicos y estudiantes eran los causantes de la fiebre puerperal. Interpretó que el origen de la fiebre puerperal eran "partículas cadavéricas pútridas" que pasaban de los cadáveres a las parturientas por acción de los médicos y parteras que las atendían. Sus medidas inmediatas fueron exitosas, obligó desde mayo de 1847 a que todos los alumnos y médicos se lavaran las manos y cepillaran las uñas con una solución clorada utilizada hasta entonces para eliminar el olor cadavérico de las manos. Los resultados fueron espectaculares, en lo que restaba del año la mortalidad bajo hasta un $3 \%$ y para 1848 se redujo hasta un 1,2\% desde cifras que habían alcanzado hasta el $30 \%$. Ya no existían diferencias entre la mortalidad de ambos servicios del mismo hospital. Estos hallazgos despertaron la aprobación de Rokitansky, Skoda y Ferdinand Hebra, discípulo de Skoda y fundador de la dermatología. El director de la maternidad Dr. Klein, atribuyó, sin embargo, la mejora a un nuevo sistema 
de ventilación que había implantado. Se iniciaba un conflicto entre dos tendencias presentes en el proceso de hegemonización de la medicina universitaria. Por un lado Klein representaba el tradicionalismo profesional no exento de base científica pero que se arraigaba en el carácter especial de la profesión médica. Por otra parte los jóvenes como Skoda y Rokitansky que a la larga triunfarían, sobreponían la evidencia a cualquier otra consideración. En esa disputa Semmelweis cometió error tras error para demostrar su descubrimiento lo que lo condujo a un trágico destino.

Casi en paralelo, pero sin la evidencia encontrada por Semmelweis, la disputa se repetía en Norteamérica. Un joven médico, Oliver Wendell Holmes, revisó lo publicado hasta la fecha sobre la fiebre puerperal y concluyó que era evidente su carácter contagioso mediado por los médicos. No discutió el modo de transmisión pero propuso como medida profiláctica el abstenerse de participar en necropsias antes de un parto. Sus ponencias, que luego sistematizaría en The contagiousness of puerperal fever (16), desataron una polémica con Charles Delucena Meiggs, profesor de obstetricia en el Jefferson's Medical College de Filadelfia, quien por su parte publicó en 1851 su obra Woman her diseases and remedies. Meiggs alude al honor y el altruismo de los médicos e intenta rebatir las ideas de Holmes, descalificándolo por su juventud en una posición claramente defensiva, mientras que su adversario convencido de la contagiosidad alude a "pestes particulares" ocasionadas por los médicos, que serán consideradas crímenes.

Semmelweis, siguiendo la tendencia experimental de la época o utilizando la emergente microscopía podía realizar experimentos que demostraran su teoría, pero si bien era un competente patólogo y obstetra no sabía cómo hacer un protocolo, pidió ayuda a un joven ayudante de Rokitansky, Georg Maria Lautner y desarrolló experimentos con conejos entre marzo y agosto de 1848. Los experimentos, mal diseñados, fueron de dos tipos; en los primeros introducía con un cepillo diversos fluidos en la vagina de conejas, en el segundo grupo lo introducía en el canal vaginal con una jeringa. Los fluidos escogidos incluían secreciones de cadáveres con diagnóstico de fiebre puerperal pero también otras enfermedades ${ }^{(17)}$. Sus resultados eran dispersos y discutibles de lo cual se aprovecharon sus adversarios. Tampoco contribuyó la aversión de Semmelweis a la escritura científica y sus limitadas capacidades de explicarse claramente cuando lo hacía. Las primeras noticias de su teoría o doctrina están en un editorial por el profesor Hebra en diciembre de 1847 referidas solo al éxito del lavado de manos con solución clorada. No tuvo repercusión, y un segundo editorial en abril de 1848 pedía opiniones. Pese a ello, la doctrina se difunde a través de médicos que visitaban el Hospital así como por cartas que Semmelweis y sus valedores enviaban. La base de la teoría de Semmelweis era la estadística antes y después de sus medidas profilácticas y no una teoría de cómo se producía la enfermedad; una explicación de esa naturaleza era incomprendida por otros médicos ya que probablemente Viena era el único hospital en el que se llevaban tan estrictos registros de los pacientes y se apreciaba su valor para validar una hipótesis, eran los comienzos de la estadística médica.

En Inglaterra, donde existía una tradición ya reseñada de considerar la fiebre puerperal como infecciosa, se entendió la doctrina de Semmelweis como una confirmación de postulados ya emitidos; pero Semmelweis se encargó de puntualizar la diferencia. El contagium era considerado una emanación que partía de un cadáver con una enfermedad determinada y que producía esa misma enfermedad en una persona sana; en cambio en el caso de la fiebre puerperal cualquier forma de pus la producía.

Culminaron los dos años de Semmelweis como asistente y el Dr. Klein, previsiblemente, no prorrogó su contrato. Rokitansky, Skoda y otros profesores hicieron todo lo posible por apoyarlo y que se quedara en la Universidad, y lograron un puesto como lecturer o conferencista, pero la influencia de Klein impuso condiciones humillantes como que no podría realizar disecciones sino solo enseñar obstetricia en un maniquí. Semmelweis no aceptó esas condiciones y súbitamente sin despedirse siquiera de sus maestros y valedores dejo Viena en dirección a su ciudad natal. Esto fue percibido por los jóvenes profesores de la universidad como una traición que nunca le perdonaron, abandonar la lucha en la cual recibió tanto apoyo dejándolos solos. En Pest, Semmelweis demoró en conseguir un trabajo, siendo húngaro y patriota su extraño acento hacia que lo percibieran como parte de los opresores austriacos, como antes había sido considerado un húngaro nacionalista intransigente en Viena. Finalmente, consiguió la dirección del Hospital de Rochus y aplicando sus medidas profilácticas disminuyó la mortalidad materna a menos del $1 \%$. Su carácter se fue agriando en tanto su doctrina era rechazada y malentendida en toda Europa, lo que en gran parte se debía a que hasta entonces no había escrito ninguna obra que la explicara adecuadamente. Tratando de resolver el tema, se dedica a escribir su única obra Die Äetiologie, der Begriff und die Prophylaxis des Kindbettfiebers (Etología, origen y profilaxis de la fiebre puerperal). Publicada en 1861, la obra es de difícil lectura, repite argumentos, se enreda en complejas demostraciones estadísticas y además no incluye nuevos experimentos. 
Los siguientes años muestran un creciente deterioro de la salud mental de Semmelweis resentido por la poca recepción de su doctrina, lo que permite continúen las altas tasa de mortalidad como en la propia Viena donde luego de su alejamiento se anulan sus medidas profilácticas. Sintiéndose el abanderado de la causa de las madres, envía cartas públicas a diversos médicos destacados injuriándolos y responsabilizándolos de las muertes. La profesión médica en un proceso de institucionalización basado en la supremacía científica y el carácter cuasisacerdotal de sus practicantes por su altruismo y entrega no acepta a este periférico médico que insulta y agrede, y además no presenta pruebas aceptables para el contexto científico de la época. Semmelweis casado y con cinco hijos colapsa y es internado en un asilo mental. Al poco tiempo muere; se ha difundido que se había herido a sí mismo intencionalmente mientras realizaba una necropsia a una víctima de la fiebre puerperal como parte de su insanía, pero una reciente revisión de archivos sugiere que fue más bien víctima de una golpiza por los enfermeros del asilo en que estuvo confinado ya que se encontraba muy agitado. De una u otra manera Semmelweis fue una víctima de un sistema que lo segregó inicialmente por su origen y su lengua, luego por sus ideas políticas $y$, posteriormente, ya en el campo profesional, por un cientifismo que solo aceptaba cierto tipo de pruebas y demostraciones vigentes en el periodo. Víctima de su propios demonios internos Semmelweis no supo corresponder a las maneras y apoyo de sus valedores y su anticipación genial a las teorías bacterianas de Koch y Pasteur debió esperar que otros médicos y científicos que siguieron los usos y costumbres de un modelo medico hegemónico lo demostraran para terminar con esta plaga de las madres.

Fuentes de financiamiento: autofinanciado.

Conflictos de interés: el autor declara no tener conflictos de interés.

\section{REFERENCIAS BIBLIOGRÁFICAS}

1. Hipócrates. Enfermedades de las mujeres. En: Tratados Hipocráticos IV. Biblioteca Clásica Gredos N. ${ }^{\circ} 114$. Madrid: Ed Gredos; 1988. p. 99-100.

2. Platter F. Praxis medica. Vol 4. Tomo III Cap. XIII De ventris dolore. Basileae: König; 1656.

3. Lesky E. The development of bedside teaching at the Vienna medical school from scholastic times to special clinics. En: Hall V (ed). UCLA Forum in medical Sciences. No 12. The History of medical education. Berkeley: University of California Press; 1970 p. 217-34

4. Lain Entralgo P. Historia de la medicina: medicina moderna y contemporánea. Barcelona: Editorial Científico Médica; 1954.

5. Strother E. Criticon febrium: or a critical essay on fevers; with the diagnosticks and methods of cure, in all the different species of them. $2^{\circ}$ ed. London; Charles Revington; 1718.

6. Hallett C. The attempt to understand puerperal fever in the eighteenth and early nineteenth centuries: the influence of inflammation theory. Med Hist. 2005;49(1):1-28.
7. Malouin M. Histoire des maladies Epidemiques de 1746 observees a Paris en meme temps que les diferentes temperaturas de l'air, depuis 1746 jusqu'a 1754 inclus. Paris; 1754

8. Hulme N. A treatise on the puerperal fever. London; 1772.

9. Hunter KR. Dr John Clarke: licenciate in midwifery of the Royal College of Physicians of London. Clin Med. 2002;2(2):153-6.

10. Loudon I, ed. Western Medicine. An illustrated history. London: Oxford University Press; 1997.

11. Gordon A. A treatise on puerperal fever of Aberdeen. London: C. G. \& J. Robinson; 1795.

12. Churchill F. An Historical sketch of the epidemics of puerperal fever. En: Churchill F. Essays on the puerperal fever and other diseases peculiar to women. London: The Sydenham Society; 1849. p. 3-41.

13. Gordon A. A treatise on the epidemic puerperal fever, etc. En: Churchill F. Essays on the puerperal fever and other diseases peculiar to women. London: The Sydenham Society; 1849. p. 445500 .
14. Bridson EY. Iatrogenic epidemics of puerperal fever in the 18th and 19th centuries. Br J Biomed Sci. 1996;53(2):134-9.

15. Carter K, Carter B. Childbed fever. A scientific biography of Ignaz Semmelweis. New Jersey: Transactions Publishers; 2009.

16. Holmes OW. The contagiousness of puerperal fever. 1848. En: The works of Oliver Wendell Holmes. Vol IX. Cambridge: Houghton Mifflin \& Company; 1892. p. 103-71.

17. Nuland SB. The doctor's plague: germs, childbed fever, and the strange story of Ignác Semmelweis. New York: WW. Norton; 2005.

Correspondencia: Oswaldo Salaverry García Dirección: Calle Cápac Yupanqui 1400, Lima 11, Perú.

Teléfono: (511) 748-0000 Axo: 1345

Correo electrónico: oswaldosalaverry@ gmail.com 